\title{
Impact of injection therapy on retinal patients with diabetic macular edema or retinal vein occlusion
}

\author{
This article was published in the following Dove Press journal: \\ Clinical Ophthalmology \\ 24 May 2016 \\ Number of times this article has been viewed
}

\section{Sobha Sivaprasad' \\ Sesan Oyetunde ${ }^{2}$}

'NIHR Biomedical Research Centre, Moorfields Eye Hospital, London, ${ }^{2}$ Allergan Holdings Ltd., Marlow, UK
Correspondence: Sobha Sivaprasad NIHR Moorfields Biomedical Research Centre, 162 City Road, London ECIV 2PD, UK

Tel +442075662039

Fax +442072993738

Email senswathi@aol.com
Purpose: An important factor in the choice of therapy is the impact it has on the patient's quality of life. This survey aimed to understand treatment burden, treatment-related anxiety and worry, and practical issues such as appointment attendance and work absence in patients receiving injection therapy for diabetic macular edema (DME) or retinal vein occlusion (RVO).

Patients and methods: A European sample of 131 retinal patients completed a detailed questionnaire to elucidate the impact of injection therapy on individuals with DME or RVO.

Results: RVO and DME greatly impact a patient's quality of life. An intensive injection regimen and the requirements for multiple hospital visits place a large practical burden on the patient. Each intravitreal injection appointment (including travel time) was reported to take an average of 4.5 hours, with a total appointment burden over 6 months of 13.5 hours and 20 hours for RVO and DME patients, respectively. This creates a significant burden on patient time and may make appointment attendance difficult. Indeed, 53\% of working patients needed to take at least 1 day off work per appointment and $71 \%$ of patients required a carer's assistance at the time of the injection appointment, $\sim 6.3$ hours per injection. In addition to practical issues, threequarters of patients reported experiencing anxiety about their most recent injection treatment, with $54 \%$ of patients reporting that they were anxious for at least 2 days prior to the injection. Patients' most desired improvement to their treatment regimen was to have fewer injections and to require fewer appointments, to achieve the same visual results.

Conclusion: Patients' quality of life is clearly very affected by having to manage an intensive intravitreal injection regimen, with a considerable treatment burden having a large negative effect. Reducing the appointment burden to achieve the same visual outcomes and the provision of additional support for patients to attend appointments would greatly benefit those receiving intravitreal injection therapies for DME and RVO.

Keywords: DME, RVO, retina, quality of life, burden, intravitreal, questionnaire

\section{Introduction}

Multiple retinal diseases, including diabetic macular edema (DME) and retinal vein occlusion (RVO), can lead to blurred and distorted vision and eventually to blindness. DME is the leading cause of vision loss in people with diabetes and affects $6.8 \%-7.5 \%$ of patients with diabetes worldwide. ${ }^{1}$ Globally, 26.7 million people are living with DME, 4 million of whom are in Europe, and many are of working age. ${ }^{1-3}$ In the future, DME is set to increase as a public health problem due to aging populations in Europe, Africa, and the Middle East and the increased prevalence of diabetes, longer duration of diabetes, and older age at onset. ${ }^{3,4}$ RVO is also an important and growing cause of vision loss, and after diabetic retinopathy, it is the most common cause of reduced vision due to retinal vascular disease. ${ }^{5-8}$ Prevalence estimates indicate that RVO affects 18.1 million people $>30$ years of age worldwide, with $\sim 2.5$ million 
of those in Europe. ${ }^{8,9}$ The development of RVO markedly increases with age, with the disease typically occurring in persons older than 50 years. ${ }^{8}$ With the proportion of people in this age group growing worldwide, the global number of RVO cases is expected to triple by $2050.5,8$

Vision loss is well known to have a negative impact on the physical functioning of a patient, limiting his or her ability to perform everyday activities, which can challenge independent living. ${ }^{10-12}$ Macular edema is one of the most common causes of vision loss following RVO and $\mathrm{DME}^{13}$ and can be chronic and difficult to treat. ${ }^{14}$ When treated quickly and appropriately, however, vision loss caused by macular edema can be halted and, in some cases, restored. Intravitreal injections with either corticosteroids or antivascular endothelial growth factors (anti-VEGFs) are both approved effective treatments for DME and RVO. ${ }^{15-18}$

An important consideration when selecting the optimal therapy for patients is the impact of the treatment on the patients' quality of life. Treatment of DME and RVO with intravitreal injections can be associated with a high appointment burden for patients, which has the potential to affect patient's quality of life in a multitude of ways. Practical factors, including time off work, ${ }^{19,20}$ and reliance on family members and/or carers to attend frequent appointment visits all affect the ability of patients to lead a normal life. ${ }^{21}$ Emotional factors, including frustration, ${ }^{22}$ frequent treatment anxiety, and needle phobia, ${ }^{23-25}$ as well as physical adverse events to the injection, which are made more probable as the number of injections increase, all need to be considered. ${ }^{26-28}$

As the number of DME and RVO patients is set to rise, now is a crucial time to understand the burden that treatment selection has on patients and on health care systems. This knowledge will enable the selection of the optimal treatment choice to promote compliance to therapy as well as optimizing resource use in increasingly challenged health care systems. The European Union market research (INCITE 2014) aimed to generate a deeper understanding of the burden of intravitreal injections on patients receiving injection therapy for DME or RVO.

\section{Patients and methods}

A European sample of 131 patients with DME $(n=86)$ or RVO ( $\mathrm{n}=45)$ completed a detailed questionnaire to elucidate the impact of injection therapy on patients' quality of life. Respondents were recruited by ophthalmologists, retina specialists, and retina nurses in each of the countries involved (Germany, Italy, and the UK) and were sent an online questionnaire in the local language when they agreed to participate. All willing respondents were sent a questionnaire, which took $\sim 20$ minutes to complete. On some occasions, the respondents preferred to complete the interview on the telephone and the recruiter then entered their data into an online form. The research included questions on patient demographics to understand the impact of intravitreal therapy in different patient populations and the practical, emotional, and physical effects faced by patients.

As this study was market research it did not require Institutional Review Board approval. Respondent approval was obtained in each country, in line with local market research practice. In addition, in the UK respondents were required to sign an agreement called "Clause 20" from the British Healthcare Business Intelligence Association.

\section{Results}

\section{Patient demographics}

The majority of interviewed patients were older than 50 years ( $88 \%$ of patients with DME and $88 \%$ of patients with RVO). Most patients were also not employed ( $80 \%$ of patients with DME and $66 \%$ of patients with RVO; Table 1).

Table I Patient demographics

\begin{tabular}{|c|c|c|}
\hline Characteristics & DME & RVO \\
\hline Patients, $\mathrm{n}$ & 86 & 45 \\
\hline \multicolumn{3}{|l|}{ Location, n } \\
\hline Germany & 35 & 15 \\
\hline$U^{a}$ & 16 & 15 \\
\hline Italy & 35 & 15 \\
\hline Male, n (\%) & $38(44)$ & $28(62)$ \\
\hline \multicolumn{3}{|l|}{ Age, $\%$} \\
\hline 18-35 years & 7 & 0 \\
\hline $36-50$ years & 5 & 11 \\
\hline $5 I-60$ years & 23 & 22 \\
\hline $61-70$ years & 42 & 33 \\
\hline$>71$ years & 23 & 33 \\
\hline \multicolumn{3}{|l|}{ Employment, \% } \\
\hline Full-time work & 12 & 20 \\
\hline Part-time work & 8 & 13 \\
\hline Retired & 58 & 53 \\
\hline Homemaker & 16 & 11 \\
\hline Other & 6 & 2 \\
\hline \multicolumn{3}{|l|}{ Treatment $^{\mathrm{b}}, \%$} \\
\hline Lucentis $^{\circledR}$ (ranibizumab) & 53 & 84 \\
\hline Avastin $^{\circledast}$ (bevacizumab) & 26 & 7 \\
\hline Ozurdex ${ }^{\circledast}$ (dexamethasone) & 3 & 2 \\
\hline Unknownc & 10 & 7 \\
\hline
\end{tabular}

Notes: ${ }^{\text {SSix }}$ patients with uveitis in the UK-only study were excluded to maintain consistency across markets for EU reporting purposes. ${ }^{\circ}$ Eylea ${ }^{\circledR}$ (aflibercept) had not received EU approval for the treatment of DME and RVO at the time that the research was conducted. Ozurdex ${ }^{\circledR}$ (dexamethasone) had not received EU approval for the treatment of DME at the time that the research was conducted. 'The name of the treatment was not included within the completed questionnaire.

Abbreviations: DME, diabetic macular edema; RVO, retinal vein occlusion; EU, European Union. 


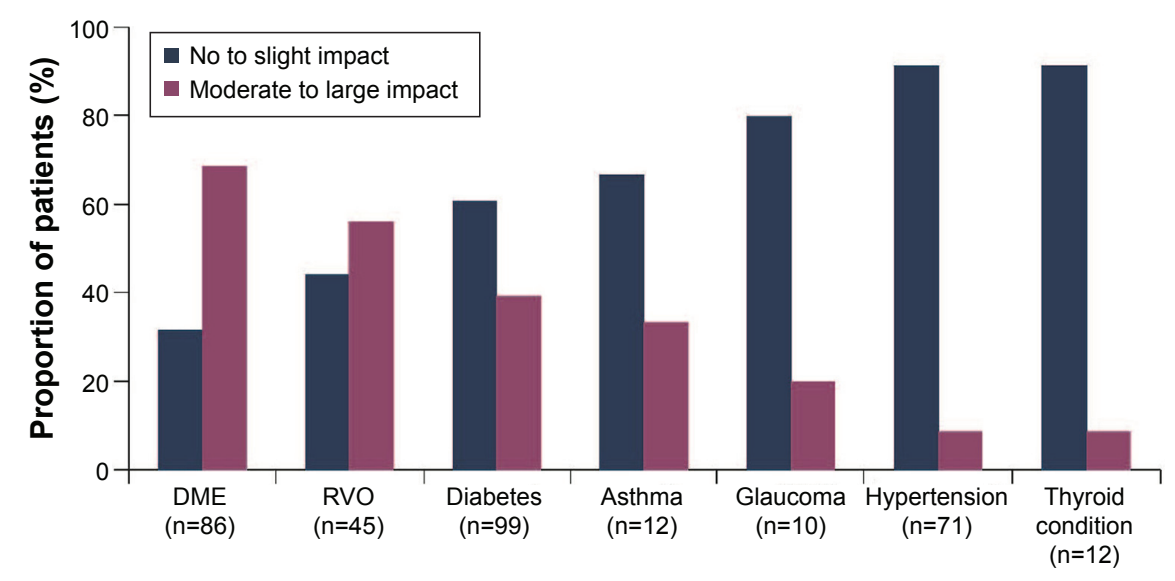

Figure I The impact of chronic conditions on patient's quality of life.

Abbreviations: DME, diabetic macular edema; RVO, retinal vein occlusion.

\section{Chronic conditions and quality of life}

In addition to the retinal disease itself, patients with DME and RVO frequently have a multitude of other comorbid conditions. As shown in Figure 1, when compared with several prevalent chronic conditions, including diabetes, asthma, and hypertension, DME and RVO have a far greater impact on the quality of life, and, of the two retinal diseases, DME has the greatest effect.

\section{Practical impact of injection therapy}

According to the patients interviewed, treatment of DME and RVO with intravitreal injection therapy and the requirement for multiple and repeated hospital visits had a large practical impact on the patient's quality of life. In terms of retinal disease treatment, the majority of patients in this research were receiving an anti-VEGF agent Lucentis ${ }^{\circledR}$ or Avastin ${ }^{\circledR}$ (Novartis Europharm Ltd, Horsham, UK) (79\% of patients with DME; $91 \%$ of patients with RVO) on a monthly regimen. Of the patients with DME, 53\% were initiated on a monthly regimen and remained on it, $27 \%$ started on a monthly regimen and switched to a less-frequent regimen, and the remainder received injections every $4-6$ months. Of the patients with RVO, $86 \%$ were initiated on a monthly regimen, $73 \%$ remained on monthly intervals, $13 \%$ moved to less frequent injections, and $13 \%$ received injections every 4-6 months (Table 1).

Each injection appointment took an average of 4.5 hours, comprising an average of 79 minutes of travel time and 188 minutes of appointment time. For the patients who work ( $\mathrm{n}=69$ ), $53 \%$ needed to take $\geq 1$ day off per appointment. The majority of patients, $71 \%$, required a carer's assistance around the time of the injection appointment, which totaled 6.3 hours of a carer's time per injection. Furthermore, 50\% of carers were employed themselves, and of those, the majority (59\%) needed to take time off to provide support to the patient.

Calculating the burden of injections over a 6-month period, more than half of patients with RVO had a mean of 9.2 appointments with retina specialists and ophthalmologists comprising an average of 10 hours 38 minutes per patient. When considering the UK only, this increased to 13.5 hours. Over the same time period, more than half of patients with DME had a mean of 19.1 appointments totaling 19 hours and 56 minutes per patient with health care professionals, including diabetologists, retina specialists, ophthalmologists, and their general practitioner, as well as additional appointments for comorbidities (Figure 2). Indeed, up to $29 \%$ of patients needed to attend appointments with specialists for their comorbidities, including neurologists, cardiologists, nephrologists and podiatrists, which greatly increased the appointment burden. For example, $29 \%$ patients had a mean of 4.1 appointments with a podiatrist totaling 3.2 hours, $25 \%$ had 1.3 appointments with an optician totaling 1 hour, and 23\% had 1.8 appointments with a neurologist totaling 2.58 hours per patient every 6 months. This creates a significant burden on patient time and may make appointment attendance difficult (Figure 2).

\section{Emotional and physical impact of injection therapy}

Three-quarters of patients reported experiencing anxiety about their most recent injection treatment, with 54\% reporting that they were anxious for $\geq 2$ days prior to treatment (Figure 3 ). When asked how their anxiety affected them prior to their most recent injection, $58 \%$ of patients reported that they were uptight and/or could not relax, $46 \%$ reported that they found it difficult to think of anything but the injection, and $26 \%$ of patients reported that their sleep was affected (Figure 3). More patients with DME reported being uptight 


\begin{tabular}{|c|c|c|c|}
\hline All EU & $\begin{array}{l}\% \text { of patients seeing an HCP } \\
\text { in the last } 6 \text { months }\end{array}$ & $\begin{array}{l}\text { Average number of times } \\
\text { seen in a } 6 \text {-month period }\end{array}$ & $\begin{array}{l}\text { Average length of appointment } \\
\text { including waiting time (min) }\end{array}$ \\
\hline Diabetologist & 73 & 3.6 & 62 \\
\hline Retina specialist & 73 & 5.1 & 76 \\
\hline Ophthalmologist & 63 & 3.7 & 64 \\
\hline $\mathrm{GP}$ & 62 & 6.7 & 45 \\
\hline Podiatrist & 29 & 4.1 & 47 \\
\hline Optician & 25 & 1.3 & 50 \\
\hline Diabetic nurse & 23 & 2.1 & 39 \\
\hline Neurologist & 23 & 1.8 & 86 \\
\hline Nurse at GP practice & 19 & 4.5 & 17 \\
\hline Cardiologist & 17 & 2.1 & 80 \\
\hline Dietician & 15 & 2.2 & 87 \\
\hline Endocrinologist & 8 & 1.1 & 66 \\
\hline Nephrologist & 1 & 6.0 & 90 \\
\hline
\end{tabular}

\section{B}

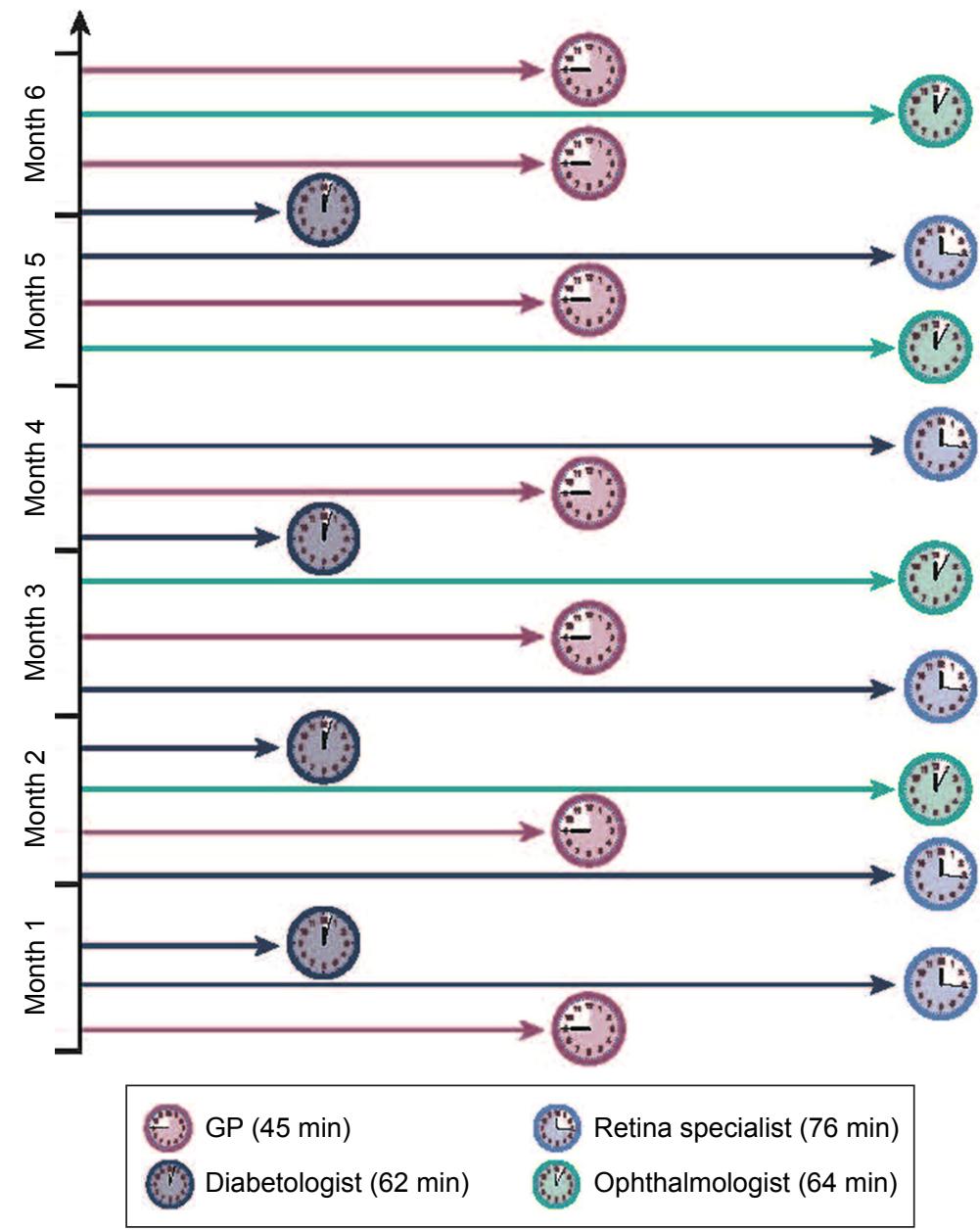

Figure 2 Appointments for patients with DME every 6 months.

Notes: (A) Appointments attended by all patients with DME every 6 months. (B) Appointment calendar for an average DME patient every 6 months. It includes all appointments held by $\geq 50 \%$ of patients. The average number of times a patient has seen a given health care professional in a 6 -month period has been rounded up or down to the nearest whole number.

Abbreviations: DME, diabetic macular edema; EU, European Union; HCP, health care provider; min, minutes; GP, general practitioner.

(62\% versus $50 \%)$, having their sleep affected $(30 \%$ versus $18 \%$ ), and having reduced concentration (17\% versus $4 \%$ ) when compared with patients with RVO. Additional reports of anxiety from patients related to needing to ask a carer for help, which led to $\sim 30 \%$ of patients feeling guilty and also added to $20 \%$ of patients' anxiety levels about their appointment.

In addition to emotional effects, $47 \%$ of patients reported having had adverse physical effects from the anxiety 
A

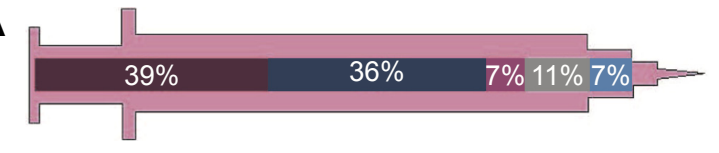

a Injection day $\square$ 2-3 days $\square$ 4-7 days $\square>1$ week $\square$ Not anxious

B

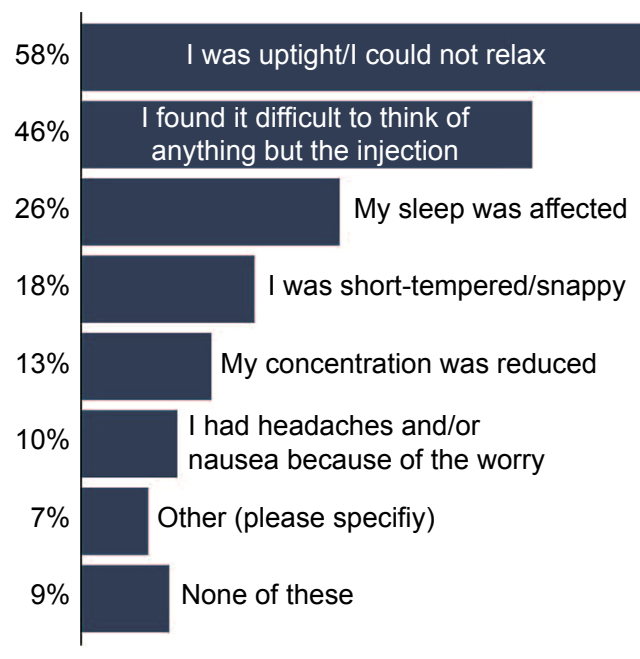

Figure 3 Impact of injection anxiety on patients.

Notes: (A) Number of days patients reported feeling anxious prior to latest intravitreal injection. (B) How anxiety prior to latest intravitreal injection manifested in patients.

experienced around the injection (such as exhaustion) as well as from the procedure itself (such as red eyes and blurry vision).

\section{Improvements to treatment regimen}

The most desired improvement to the treatment regimen, requested by $42 \%$ of patients, was to have fewer injections to achieve the same visual results (Figure 4). In addition, the requirement for fewer appointments to achieve the same results was rated as the most desired improvement by $22 \%$ of patients. Factors to reduce the overall practical impact of each appointment, including reducing appointment waiting time and having treatment carried out closer to home, were also requested.

\section{Discussion}

In this research, DME and RVO had a greater impact on patients' quality of life than other common chronic conditions, including diabetes, asthma, and hypertension, and, of the two retinal diseases, DME has a larger effect. These findings support those from multiple studies that have clearly shown the heavy emotional and practical burden that retinal diseases place on patients. ${ }^{10,11,29-32}$ In DME, the impact on the quality of life increases as vision impairment and severity of DME worsen. ${ }^{32}$ A reduced quality of life can hinder the patients' ability to manage their diabetes, worsening their disease and exacerbating complications. ${ }^{20}$ Licensed treatments are available for preventing/restoring

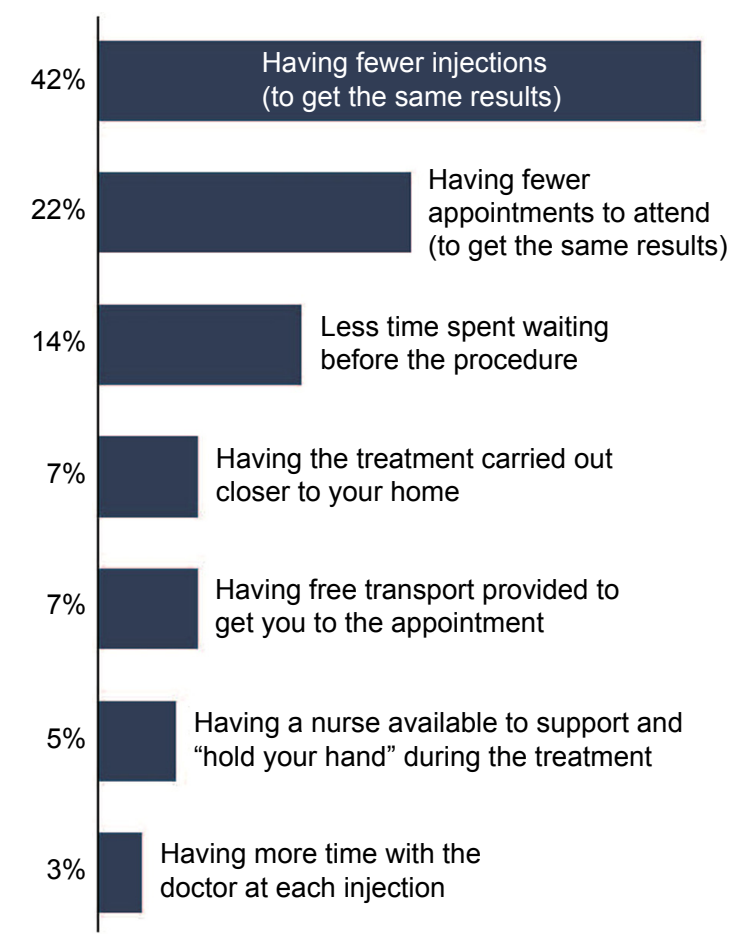

Figure 4 Desired improvements to the injection treatment regimen.

vision loss associated with DME and RVO but can be associated with a large treatment burden, requiring patients to attend monthly appointments. The majority of patients with DME (79\%) and RVO (91\%) in this research were being treated with anti-VEGF agents. The number of intravitreal injections required with anti-VEGFs is greater than that with corticosteroids, such as Ozurdex ${ }^{\circledR}$ (Allergan, Inc., Irvine, CA, USA) (0.7 mg dexamethasone) and Iluvien ${ }^{\circledR}$ (Alimera Sciences, Alpharetta, GA, USA) (fluocinolone acetonide), and the injection regimen associated with antiVEGF efficacy in clinical trials (7-12 injections/year) may be difficult to achieve in clinical practice. ${ }^{26,33,34}$ In addition, antiVEGF therapies have a greater number of injection treatment review visits, irrelevant of whether the patient is on a pro re nata or treat-and-extend regimen; an average of 21-36 injection treatment review visits are reported in a 3-year period versus seven injection review visits for Ozurdex ${ }^{\circledR}$ over the same time period. ${ }^{15,16,35-38}$ Ozurdex $^{\circledR}$ is indicated for the treatment of adult patients with visual impairment due to DME who are pseudophakic or who are considered insufficiently responsive to or unsuitable for noncorticosteroid therapy and for the treatment of adult patients with macular edema following either branch RVO or central RVO. ${ }^{17}$ Iluvien $^{\circledR}$ is indicated for the treatment of vision impairment associated with chronic DME, considered insufficiently responsive to available therapies (comprising anti-VEGF agents, other corticosteroids, or laser). ${ }^{18}$ 
In this study, a 6-month period was associated with $\sim 20$ hours of appointment burden per patient for people with DME and $\sim 11$ hours for patients with RVO across Europe. This clear difference in appointment burden between patients with DME and those with RVO reveals the additional visits that patients with DME must attend for their diabetes and associated comorbidities. National guidelines across the European Union Five (France, Germany, Italy, Spain, UK) recommend at least quarterly visits to an endocrinologist or a diabetologist for stable patients with diagnosed diabetes to monitor the potential development of diabetes-related complications. ${ }^{39}$ The majority of people with diabetes have at least one comorbid disease, and up to $40 \%$ have at least three, increasing the number of appointments required..$^{40}$

Patients with DME and RVO who face multiple intravitreal injections experience high levels of anxiety; fewer injections would therefore assist in the reduction of anxiety experienced by patients. Patients with multiple injection appointments also have an increased risk of noncompliance to therapies as they find it burdensome. Moreover, for those patients with DME, trying to attend all clinic visits regarding their DME and additional diabetes comorbidity clinic visits (such as cardiovascular, podiatry, nephrology, GP, etc) could impact their ability to lead a normal life. ${ }^{26,28,35,36,41}$ Of note, although the number of patients are too small for analysis in this study, patients younger than 50 years of age $(n=14)$ reported higher levels of anxiety than patients older than 50 years $(n=117)$. In addition, patients in Germany $(n=33)$ appear to be more anxious before an upcoming injection than patients in Italy $(\mathrm{n}=45)$ and the UK $(\mathrm{n}=20)$. These trends are worthy of additional research in future studies.

A reduced number of intravitreal injections could reduce the burden of care for patients and optimize patient disease outcomes, potentially by promoting improved compliance. ${ }^{41}$ Feedback from patients in this research clearly showed that reducing the number of injections for the same visual results is considered to be the most important improvement to treatment. In addition to the burden on patients, frequent injections are also an added burden to ophthalmologists with an already demanding workload and who can only spend a limited amount of time with each patient. ${ }^{22,40}$

With an increasing number of people developing DME and RVO, capacity issues for clinics and overstretching of resources is an important consideration. The Royal National Institute of Blind People conducted a survey of staff from eye clinics across England. More than $80 \%$ of respondents reported that their department had insufficient capacity to meet current demand for services. ${ }^{42}$ The frequency of
anti-VEGF injections may result in clinics reaching their capacity levels and resources (funds and/or staff) being redirected from other eye care services to support anti-VEGF clinic appointments. ${ }^{42}$

In this study, patients frequently needed to take time off work and rely on carers, and in addition to being a large burden to the patient, this is associated with a high economic burden. Total annual costs for visually impaired people in the UK, Italy, Germany, and France ranged from $€ 9,214$ million to $€ 15,180$ million. The main cost components of visual impairment in the community were "loss of income" (23\%-43\% of community costs), "burden on carer" (24\%-39\%), and "paid assistance" (13\%-29\%). The average annual costs per affected individual ranged from $€ 8,434$ to $€ 13,674 .{ }^{43}$ Across Europe, the direct annual cost per patient with DME is $\_31,000$, which is mainly attributable to outpatient visits, inpatient care, nursing care, and pharmacological therapy. ${ }^{44}$ DME also generates substantial indirect medical costs $\left(€ 11,500\right.$ per patient per annum $\left.{ }^{44}\right)$, including those related to home adaptation or the requirement of assistance with daily tasks, and is also associated with significant indirect costs from absenteeism from work. ${ }^{19}$ Limited data are available for costs related to RVO; a US study of elderly Medicare beneficiaries found that the direct health care costs associated with RVO are higher than those for hypertension or glaucoma. ${ }^{45}$

Fewer intravitreal injections for the treatment of DME and RVO will reduce the overall appointment burden as well as reliance on carers and time off work. Not only will this reduce the patients' societal and economic burden, it will also act to alleviate the capacity issues being faced by overstretched health care systems. Additional support in alleviating travel burden (including cost/planning) would likely be welcomed by patients. Offering activities that patients could become involved in during appointment waiting times to offer distraction and reduce stress may also be of benefit. Potential opportunities for closer working between ophthalmology and diabetes services should be explored for patients with DME to attempt to coordinate patient appointment schedules.

\section{Conclusion}

This research improves understanding of the far-reaching effects that treatment burden and appointment schedules have on patients with DME and RVO. These interesting data warrant further investigation in a larger European patient population. Reducing the appointment burden and providing better support for patients would benefit those receiving intravitreal injection therapies for DME and RVO. This research provides additional 
considerations for clinicians when they are making their decision as to the optimal therapeutic choice for their patients. Treatments associated with fewer injections could help to reduce patient burden as well as their reliance on carers. In addition, less frequent treatment regimens could also reduce economic burden and may help to alleviate the impact on health care systems, an important consideration in light of the burgeoning numbers of people developing these retinal diseases.

\section{Acknowledgments}

The authors are thankful to National Institute for Health Research (NIHR) Moorfields Biomedical Research Centre for supporting Sobha Sivaprasad to conduct this study. Medical writing support was provided by Katherine Smith of Synergy Medical.

\section{Disclosure}

Sobha Sivaprasad is a consultant to Allergan, Novartis, Roche, and Bayer and has received travel grants, research grants, and speaker fees from these companies. Sesan Oyetunde is an employee of Allergan Holdings Ltd. The authors report no other conflicts of interest in this work.

\section{References}

1. Yau JW, Rogers SL, Kawasaki R, et al. Global prevalence and major risk factors of diabetic retinopathy. Diabetes Care. 2012;35:556-564.

2. Minassian DC, Owens DR, Reidy A. Prevalence of diabetic macular oedema and related health and social care resource use in England. Br J Ophthalmol. 2012;96:345-349.

3. International Diabetes Federation [webpage on the Internet]. IDF Diabetes Atlas. 6th ed; 2013 [cited May, 2015]. Available from: http:// www.idf.org/diabetesatlas. Accessed March 8, 2016.

4. Ding J, Wong TY. Current epidemiology of diabetic retinopathy and diabetic macular oedema. Curr Diab Rep. 2012;12:346-354.

5. Royal College of Ophthalmologists. Guidelines for Retinal Vein Occlusion. London: Royal College of Ophthalmologists; 2015.

6. Klein R, Klein BE, Moss SE, Meuer SM. The epidemiology of retinal vein occlusion: the Beaver Dam Eye Study. Trans Am Ophthalmol Soc. 2000;98:133-141.

7. Rehak J, Rehak M. Branch retinal vein occlusion: pathogenesis, visual prognosis and treatment modalities. Curr Eye Res. 2008;33:111-131.

8. Laouri M, Chen E, Looman M, Gallagher M. The burden of disease of retinal vein occlusion: review of the literature. Eye. 2011;25: 981-988.

9. US Census information [webpage on the Internet]. International Data Base [cited May, 2015]. Available from: http://www.census.gov/ population/international/data/idb/informationGateway.php. Accessed March 8, 2016.

10. Hariprasad SM, Mieler WF, Grassi M, Green JL, Jager RD, Miller L. Vision-related quality of life in patients with diabetic macular oedema. Br J Ophthalmol. 2008;92:89-92.

11. Klein R, Moss SE, Klein BE, Gutierrez P, Mangione CM. The NEIVFQ-25 in people with long term type 1 diabetes mellitus. Arch Ophthalmol. 2001;119:733-740.

12. Christ SL, Zheng DD, Swenor BK, et al; Meta-Analysis for Eye Disease (META-EYE) Study Group. Longitudinal relationships among visual acuity, daily functional status, and mortality: the Salisbury Eye Evaluation Study. JAMA Ophthalmol. 2014;132:1400-1406.
13. Weinberg DV, Seddon JM. Venous occlusive diseases of the retina. In: Albert DM, Jakobiec FA, editors. Principles and Practice of Ophthalmology. Vol. 2. Philadelphia: W.B. Saunders Company; 1994: 735-746.

14. Johnson MW. Etiology and treatment of macular oedema. Am J Ophthalmol. 2009;147:11-21.

15. Lucentis $10 \mathrm{mg} / \mathrm{mL}$ solution for injection. [webpage on the Internet]. EMC+. Novartis Pharmaceuticals UK, Ltd; 2016. Available from https://www. medicines.org.uk/emc/medicine/19409. Accessed April 28, 2016.

16. Eylea $40 \mathrm{mg} / \mathrm{mL}$ solution for injection in a vial. [webpage on the Internet]. EMC $\mathrm{EM}^{+}$Bayer plc; 2016. Available from https://www.medicines. org.uk/emc/medicine/27224. Accessed April 28, 2016.

17. Ozurdex. [webpage on the Internet]. EMC ${ }^{+}$. Allergen Ltd; 2015. Available from https://www.medicines.org.uk/emc/medicine/23422. Accessed April 28, 2016.

18. ILUVIEN 190 micrograms intravitreal implant in applicator. [webpage on the Internet]. $\mathrm{EMC}^{+}$. Alimera Sciences; 2015. Available from https://www. medicines.org.uk/emc/medicine/27636. Accessed April 28, 2016.

19. Lee LJ, Yu AP, Cahill KE, et al. Direct and indirect costs among employees with diabetic retinopathy in the United States. Curr Med Res Opin. 2008;24:1549-1559.

20. Chen E, Looman M, Laouri M, et al. Burden of illness of diabetic macular edema: literature review. Curr Med Res Opin. 2010;26:1587-1596.

21. Access Economics [webpage on the Internet]. Future sight loss in the UK (1): the economic impact of partial sight and blindness in the UK adult population. Full report. Report prepared for RNIB; 2009 [cited May, 2015]. Available from: www.rnib.org.uk/aboutus/ Research/reports/2009andearlier/FSUK_Report.pdf. Accessed March 8, 2016.

22. Appiah A [webpage on the Internet]. Retinal Physician; 2013 [cited May, 2015]. Available from: http://www.iridex.com/Portals/0/dme/ Appiah-532-MPLT-Retinal-Physician-2013.pdf. Accessed March 8, 2016.

23. Fu AZ, Qiu Y, Radican L. Impact of fear of insulin or fear of injection on treatment outcomes of patients with diabetes. Curr Med Res Opin. 2009; 25:1413-1420.

24. Chen X, Seth RK, Rao VS, Huang JJ, Adelman RA. Effects of music therapy on intravitreal injections: a randomized clinical trial. $J$ Ocul Pharmacol Ther. 2012;28:414-419.

25. AADE Guide Diabetes Self-Management. A Guide to Encouraging Your Patients to Speak about Their Injections. Chicago, IL: AADE; 2010.

26. Nguyen QD, Brown DM, Marcus DM, et al; RISE and RIDE Research Group. Ranibizumab for diabetic macular edema: results from 2 phase III randomized trials: RISE and RIDE. Ophthalmology. 2012;119:789-801.

27. Do DV, Nguyen QD, Boyer D, et al; da Vinci Study Group. One-year outcomes of the da Vinci Study of VEGF Trap-Eye in eyes with diabetic macular edema. Ophthalmology. 2012;119:1658-1665.

28. Gillies MC, Lim LL, Campain A, et al. A randomized clinical trial of intravitreal bevacizumab versus intravitreal dexamethasone for diabetic macular edema: the BEVORDEX study. Ophthalmology. 2014; 121:2473-2481.

29. Elsing SH, Shidhaye N, Deramo VA. Vision-related quality of life in patients with branch retinal vein occlusion (RVO) using the National Eye Institute Visual Functioning Questionnaire-25 (VFQ-25). Invest Ophthalmol Vis Sci. 2001;42:S236. [Abstract 1273-B586].

30. Awdeh RM, Elsing SH, Deramo VA, Stinnett S, Lee PP, Fekrat S. Vision-related quality of life in persons with branch retinal vein occlusion (BRVO) using the 25-item NEI Visual Function Questionnaire. Br J Ophthalmol. 2010;94:319-323.

31. Deramo VA, Cox TA, Syed AB, Lee PP, Fekrat S. Vision-related quality of life in people with central retinal vein occlusion using the 25-item National Eye Institute Visual Function Questionnaire. Arch Ophthalmol. 2003;121:1297-1302.

32. Fenwick EK, Xie J, Ratcliffe J, et al. The impact of diabetic retinopathy and diabetic macular edema on health-related quality of life in type 1 and type 2 diabetes. Invest Ophthalmol Vis Sci. 2012;53:677-684. 
33. Campbell J, Cole AL, Almony A, et al. Real World Vision Outcomes in DMO Treated with Anti-VEGF Injections - An Analysis of EMR Data From a Large Health System 2014. Abstract 3065 Presented at: ARVO 2014; Orlando, FL.

34. Kiss S, Liu Y, Brown J, et al. Clinical utilization of anti-vascular endothelial growth-factor agents and patient monitoring in retinal vein occlusion and diabetic macular edema. Clin Ophthalmol. 2014;8: 1611-1621.

35. Brown DM, Nguyen QD, Marcus DM, et al; RIDE and RISE Research Group. Long-term outcomes of ranibizumab therapy for diabetic macular edema: the 36-month results from two phase III trials: RISE and RIDE. Ophthalmology. 2013;120:2013-2022.

36. Boyer DS, Yoon YH, Belfort R Jr, et al; Ozurdex MEAD Study Group. Three-year, randomized, sham-controlled trial of dexamethasone intravitreal implant in patients with diabetic macular edema. Ophthalmology. 2014;121:1904-1914.

37. Mitchell P, Bandello F, Schmidt-Erfurth U, et al; RESTORE Study Group. The RESTORE study: ranibizumab monotherapy or combined with laser versus laser monotherapy for diabetic macular edema. Ophthalmology. 2011;118:615-625.

38. Korobelnik JF, Do DV, Schmidt-Erfurth U, et al. Intravitreal aflibercept for diabetic macular edema. Ophthalmology. 2014;121:2247-2254.
39. Kanavos $P$, van den Aardweg S, Schurer W [webpage on the Internet]. Diabetes expenditure, burden of disease and management in 5 EU countries [cited May, 2015]. Available from: http://www.lse.ac.uk/LSEHealthAndSocialCare/research/LSEHealth/MTRG/LSEDiabetesReport26Jan2012. pdf. Accessed March 8, 2016.

40. Piette JD, Kerr EA. The impact of comorbid chronic conditions on diabetes care. Diabetes Care. 2006;29:725-731.

41. Vijan S, Hayward RA, Ronis DL, Hofer TP. Brief report: the burden of diabetes therapy: implications for the design of effective patientcentered treatment regimens. J Gen Intern Med. 2005;20:479-482.

42. RNIB [webpage on the Internet]. Saving Money, Losing Sight. RNIB Campaign Report; 2013 [cited May, 2015]. Available from: http:// www.rnib.org.uk/sites/default/files/Saving\%20money\%20losing\%20 sight\%20Campaign\%20report_0.pdf. Accessed March 8, 2016.

43. Lafuma A, Brézin A, Lopatriello S, et al. Evaluation of non-medical costs associated with visual impairment in four European countries: France, Italy, Germany and the UK. Pharmacoeconomics. 2006;24: 193-205.

44. Busuttil S. Vision for the future. Parliament Mag. 2011;320:23.

45. Fekrat S, Shea AM, Hammill BG, et al. Resource use and costs of branch and central retinal vein occlusion in the elderly. Curr Med Res Opin. 2010;26:223-230.
Clinical Ophthalmology

\section{Publish your work in this journal}

Clinical Ophthalmology is an international, peer-reviewed journal covering all subspecialties within ophthalmology. Key topics include: Optometry; Visual science; Pharmacology and drug therapy in eye diseases; Basic Sciences; Primary and Secondary eye care; Patient Safety and Quality of Care Improvements. This journal is indexed on

\footnotetext{
Submit your manuscript here: http://www.dovepress.com/clinical-ophthalmology-journal
}

\section{Dovepress}

PubMed Central and CAS, and is the official journal of The Society of Clinical Ophthalmology (SCO). The manuscript management system is completely online and includes a very quick and fair peer-review system, which is all easy to use. Visit http://www.dovepress.com/ testimonials.php to read real quotes from published authors. 